\title{
Introduction of a New Staging System of Breast Cancer for Radiologists: An Emphasis on the Prognostic Stage
}

\author{
Jieun Koh, $M D^{1,2}$, Min Jung Kim, MD, $\mathrm{PhD}^{1}$ \\ ${ }^{1}$ Department of Radiology, Severance Hospital, Research Institute of Radiological Science, Yonsei University College of Medicine, Seoul, Korea; \\ ${ }^{2}$ Department of Radiology, CHA Bundang Medical Center, CHA University, Seongnam, Korea
}

In 2017, the American Joint Committee on Cancer announced the 8th edition of its cancer staging system. For breast cancer, the most significant change in the staging system is the incorporation of biomarkers into the anatomic staging to create prognostic stages. Different prognostic stages are assigned to tumors with the same anatomic stages according to the tumor grade, hormone receptor (estrogen receptor; progesterone receptor) status, and HER2 status. A Clinical Prognostic Stage is assigned to all patients regardless of the type of therapy used; in contrast, a Pathologic Prognosis Stage is assigned to patients in whom surgery is the initial treatment. In a few situations, low Oncotype DX recurrence scores can change the prognostic stage. The radiologists need to understand the importance of the biologic factors that can influence cancer staging. Keywords: Breast neoplasm; TNM stage; Biomarker; AJCC; Prognostic stage

\section{INTRODUCTION}

Since 1959, the American Joint Committee on Cancer (AJCC) has published seven editions of the tumor-nodemetastasis (TNM) system for cancer staging. In 2017, the 8th edition was announced, in which the revisions were based on the highest level of evidence from newly acquired clinical and pathological data (1). In a fundamental change, breast cancer is now considered as a group of diseases with different molecular characteristics that indicate different prognoses, patterns of recurrence, disseminations, and sensitivities to available therapies (2). Therefore, the

Received April 12, 2018; accepted after revision July 9, 2018. This study was supported by the Basic Science Research Program of the National Research Foundation of Korea funded by the Ministry of Science, ICT \& Future Planning, Republic of Korea (grant 2017R1A2B4010407).

Corresponding author: Min Jung Kim, MD, PhD, Department of Radiology, Severance Hospital, Research Institute of Radiological Science, Yonsei University College of Medicine, 50-1 Yonsei-ro, Seodaemun-gu, Seoul 03722, Korea.

- Tel: (822) 2228-7400 - Fax: (822) 393-3035

- E-mail: mines@yuhs.ac

This is an 0pen Access article distributed under the terms of the Creative Commons Attribution Non-Commercial License (https://creativecommons.org/licenses/by-nc/4.0) which permits unrestricted non-commercial use, distribution, and reproduction in any medium, provided the original work is properly cited. committee incorporated biomarkers (histologic grade, hormone receptor, HER2 expression, and multigene panels) into the traditional anatomic TNM staging (1). Here, we introduce the major changes of the 8th edition of the AJCC staging system of breast cancer to radiologists, by presenting representative cases that will be staged differently under the new system. The changes in the 8th edition are briefly summarized in Table 1 .

\section{Brief Overview of the 7th Edition}

The 7th edition of the AJCC staging system was mainly based on anatomical staging, which used the extent of the primary tumor $(T)$, status of the regional lymph nodes $(\mathrm{N})$, and metastasis status (M). This has remained largely unchanged in the 8th edition. The T stage is based on the size and degree of loco-regional invasion by the primary tumor and is categorized from T1 to T4. The N stage is determined by the extent of nodal involvement including axillary, internal mammary, and ipsilateral supraclavicular lymph nodes. Distant metastases are evaluated to determine the $M$ stage. The 7th edition used nine stages (0, IA, IB, IIA, IIB, IIIA, IIIB, IIIC, and IV) based on different combinations of $\mathrm{T}, \mathrm{N}$, and $\mathrm{M}$ status (Table 2). 
Table 1. Summary of Changes in 8th Edition

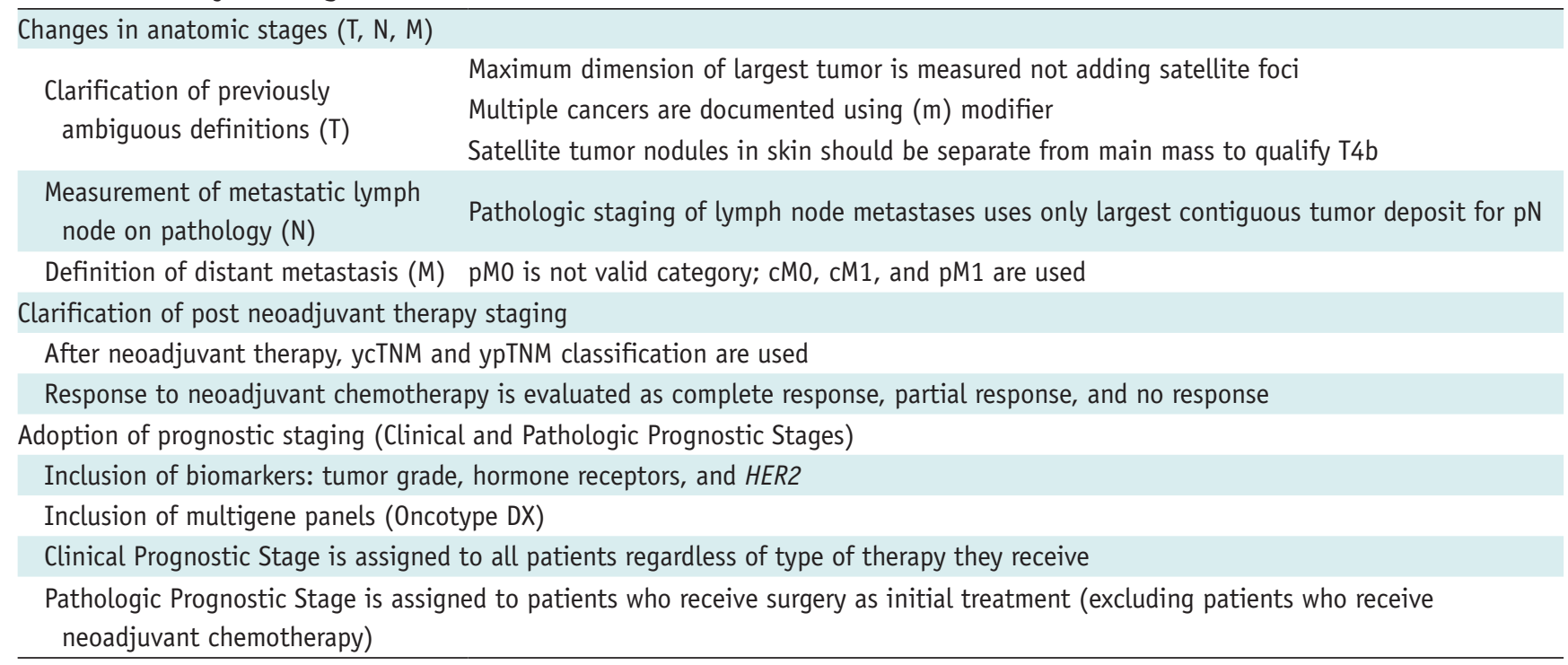

$\mathrm{M}=$ metastasis, $\mathrm{N}=$ nodes, $\mathrm{pN}=$ pathologic $\mathrm{N}, \mathrm{T}=$ tumor, $\mathrm{TNM}=$ tumor-node-metastasis

Table 2. 7th Edition of American Joint Committee on Cancer Staging System for Breast Cancer

\begin{tabular}{|c|c|c|c|}
\hline Stage & Tumor & Node & Metastasis \\
\hline 0 & Tis & NO & MO \\
\hline IA & $\mathrm{T} 1$ & NO & MO \\
\hline \multirow[t]{2}{*}{ IB } & T0 & $\mathrm{N} 1 \mathrm{mi}$ & MO \\
\hline & T1 & $\mathrm{N} 1 \mathrm{mi}$ & MO \\
\hline \multirow[t]{3}{*}{ IIA } & T0 & N1 & MO \\
\hline & $\mathrm{T} 1$ & N1 & MO \\
\hline & T2 & No & MO \\
\hline \multirow[t]{2}{*}{ IIB } & T2 & N1 & MO \\
\hline & T3 & No & MO \\
\hline \multirow[t]{5}{*}{ IIIA } & T0 & N2 & MO \\
\hline & T1 & N2 & MO \\
\hline & T2 & N2 & MO \\
\hline & T3 & N1 & MO \\
\hline & T3 & N2 & MO \\
\hline \multirow[t]{3}{*}{ IIIB } & T4 & NO & MO \\
\hline & T4 & N1 & MO \\
\hline & T4 & N2 & MO \\
\hline IIIC & AnyT & N3 & MO \\
\hline IV & AnyT & AnyN & M1 \\
\hline
\end{tabular}

Tis = in situ, $\mathrm{mi}=$ micrometasis

\section{Changes in the Anatomic Stage}

The AJCC committee maintained the anatomic stages for countries in which the tests for biomarkers were unavailable and for uniformity in terminology with past studies and different researchers. In the 8th edition, the fundamental rules for anatomic staging have not been changed, but several previous ambiguous definitions have been clarified.

Tumor

In the 8th edition, lobular carcinoma in situ has been removed from the in situ carcinoma (pTis) category and classified as a benign entity. Except for invasive carcinoma and ductal carcinoma in situ (DCIS) being included in the staging system, the criteria for the T categories remain the same as those in the 7th edition. DCIS and Paget disease of the nipple, not associated with parenchymal carcinoma, are classified as Tis (DCIS) and Tis (Paget disease). Categories T1-3 have been assigned to an invasive carcinoma without loco-regional invasion according to the size of the invasive component (Table 3 ). For staging, the maximum invasive tumor size is measured because it is a reasonable estimate of the tumor volume (Fig. 1) (3). The 8th edition clarifies that only the maximum dimension of the largest tumor is measured, without adding small microscopic satellite foci of the tumor. In that case, multiple cancers are documented using the modifier (m) (Fig. 2). On imaging, the measurement of the largest tumor should be combined with the size of microcalcifications or architectural distortions associated with the primary tumor, because they could influence the surgical extent. The T1 category is defined as a tumor of $20 \mathrm{~mm}$ or less and is divided into T1 $\mathrm{mi}(\leq$ $1 \mathrm{~mm}), \mathrm{T} 1 \mathrm{a}$ (> $1 \mathrm{~mm}$ but $\leq 5 \mathrm{~mm}), \mathrm{T} 1 \mathrm{~b}(>5 \mathrm{~mm}$ but $\leq 10$ $\mathrm{mm})$, and T1c (> $10 \mathrm{~mm}$ but $\leq 20 \mathrm{~mm}) ;$ T2 category are tumors $>20 \mathrm{~mm}$ but $\leq 50 \mathrm{~mm}$; T3 category are tumors $>50 \mathrm{~mm}$ (1). The T4 category is assigned when there is 
Table 3. Definition of Primary T Categories

\begin{tabular}{|c|c|}
\hline Stage & Definition \\
\hline$\overline{T X}$ & Primary tumor cannot be assessed \\
\hline T0 & No evidence of primary tumor \\
\hline Tis (DCIS) & Ductal carcinoma in situ \\
\hline Tis (Paget's) & $\begin{array}{l}\text { Paget's disease of nipple NOT associated with invasive carcinoma and/or carcinoma in situ (DCIS) in underlying breast } \\
\text { parenchyma. Carcinomas in breast parenchyma associated with Paget disease are categorized based on size and } \\
\text { characteristics of parenchymal disease, although presence of Paget disease should still be noted }\end{array}$ \\
\hline T1 & Tumor $\leq 20 \mathrm{~mm}$ in greatest dimension \\
\hline T1mi & Tumor $\leq 1 \mathrm{~mm}$ in greatest dimension \\
\hline T1a & Tumor $>1 \mathrm{~mm}$ but $\leq 5 \mathrm{~mm}$ in greatest dimension (round any measurement $1.0-1.9 \mathrm{~mm}$ to $2 \mathrm{~mm}$ ) \\
\hline $\mathrm{T} 1 \mathrm{~b}$ & Tumor $>5 \mathrm{~mm}$ but $\leq 10 \mathrm{~mm}$ in greatest dimension \\
\hline T1c & Tumor $>10 \mathrm{~mm}$ but $\leq 20 \mathrm{~mm}$ in greatest dimension \\
\hline T2 & Tumor $>20 \mathrm{~mm}$ but $\leq 50 \mathrm{~mm}$ in greatest dimension \\
\hline T3 & Tumor $>50 \mathrm{~mm}$ in greatest dimension \\
\hline T4 & $\begin{array}{l}\text { Tumor of any size with direct extension to chest wall and/or to skin (ulceration or macroscopic nodules); } \\
\text { invasion of dermis alone does not qualify as T4 }\end{array}$ \\
\hline T4a & Extension to chest wall, not including only pectoralis muscle adherence/invasion \\
\hline T4b & $\begin{array}{l}\text { Ulceration and/or ipsilateral macroscopic satellite nodules and/or edema (including peau d'orange) of skin, } \\
\text { which do not meet criteria for inflammatory carcinoma }\end{array}$ \\
\hline T4C & Both T4a and T4b \\
\hline T4d & Inflammatory carcinoma \\
\hline
\end{tabular}

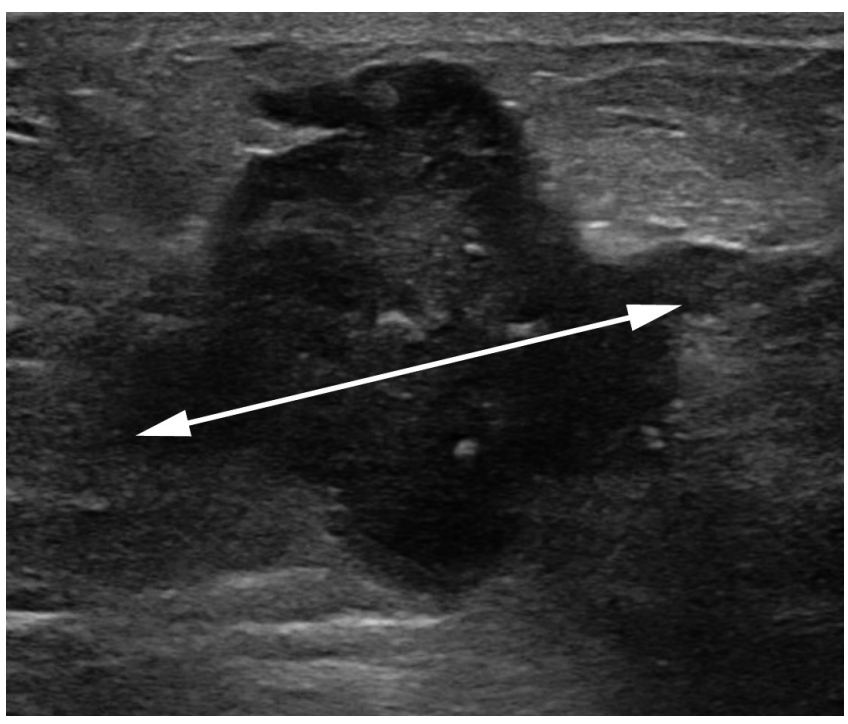

Fig. 1. Measurement of tumor size. Maximum tumor size measures $4.3 \mathrm{~cm}$ on ultrasound image (arrow). It also measures $4.3 \mathrm{~cm}$ pathologically. Therefore, both clinical and pathologic T category is T2. $\mathrm{T}$ = tumor

either chest wall or skin invasion by the breast cancer cells. Extension into the chest wall is T4a category and it means invasion of the ribs, intercostal muscles, and serratus anterior muscle; however, invasion of only the pectoral muscles does not qualify as T4. Magnetic resonance imaging (MRI) provides a more accurate assessment of chest wall extension than mammography or ultrasound (4). Satellite tumor nodules in the skin are T4b, but the nodules must be separate from the primary tumor and macroscopically identified (Fig. 3). Ulceration or edema of less than onethird of the skin of the breast, which does not qualify as inflammatory breast cancer (IBC), is regarded as T4b. On the MRI, direct skin invasion causes skin thickening, multiple nodules, ulceration, and a fungating mass (5). Invasion of the dermis alone does not qualify as T4; a T4c category is determined when conditions of both $\mathrm{T} 4 \mathrm{a}$ and $\mathrm{T} 4 \mathrm{~b}$ are met (Fig. 4). IBC (T4d) is primarily a clinical diagnosis made when diffuse erythema and edema involving at least onethird of the skin of the breast is observed (Fig. 5). It is highly aggressive with rapid evolution and is associated with poor prognosis $(6,7)$; therefore, a neglected, locally advanced breast cancer should not be classified as IBC. On mammography, IBC presents as diffuse skin thickening and trabecular distortion, whereas, on ultrasound, it presents a mass or parenchymal distortion and diffuse skin thickening. On MRI, the primary lesions present mostly as multiple small, confluent, enhancing nodules accompanied with diffuse skin thickening $(8,9)$. For the T staging of breast cancer on imaging, the longest diameter should be measured, multiple tumor nodules should be identified, and loco-regional invasion should be evaluated by careful examination of the nipple, skin, and underlying chest wall. 


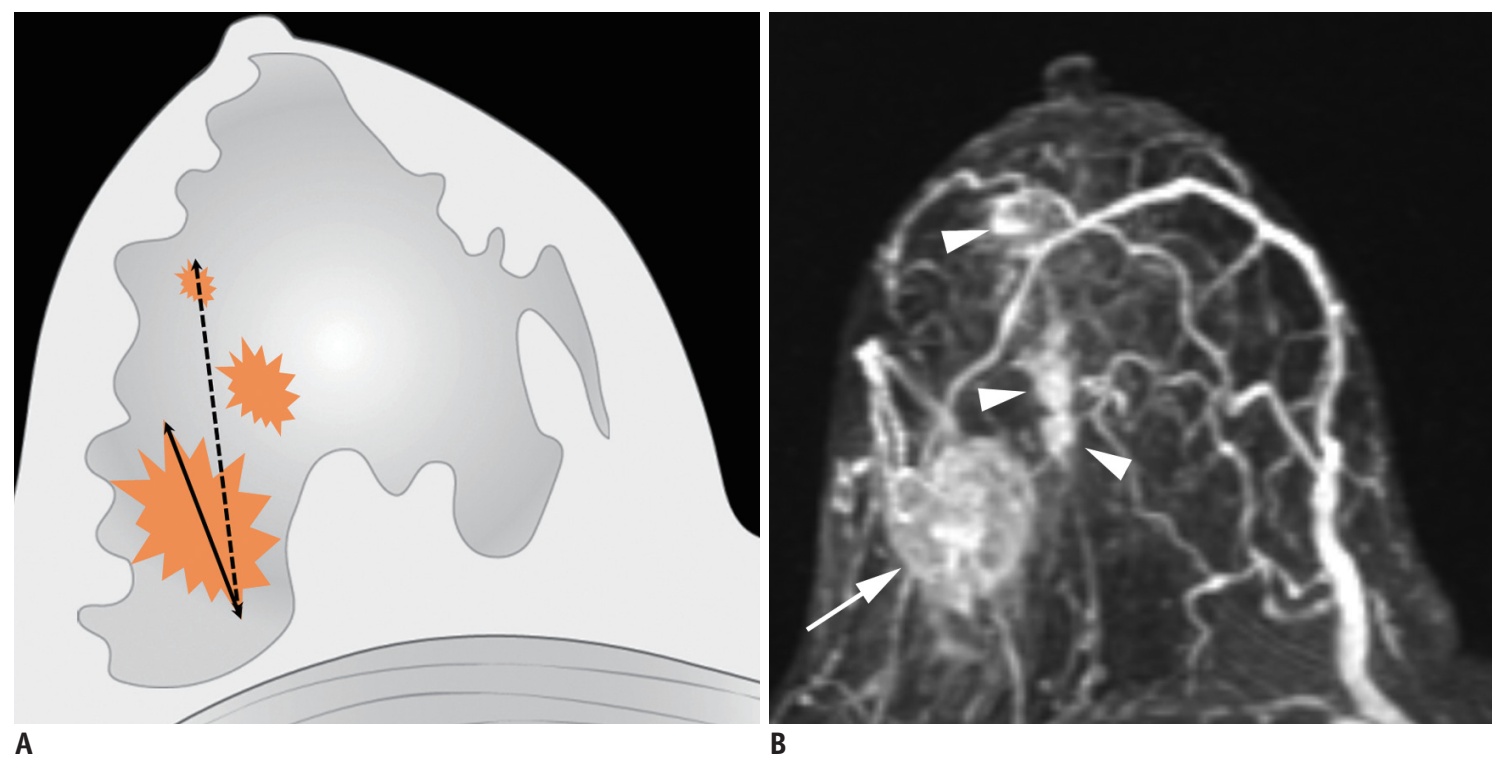

Fig. 2. Determination of $\mathrm{T}$ categories.

A. Maximum size of largest tumor is measured (solid line), but size of smaller tumors is not added (dotted line). B. Magnetic resonance maximum intensity projection image demonstrates multiple synchronous tumors in breast. Maximum invasive size of largest tumor is $2.4 \mathrm{~cm}$ (arrow), and size of smaller tumors (arrowheads) is not added. Therefore, cT2 (m) is designated for T stage.

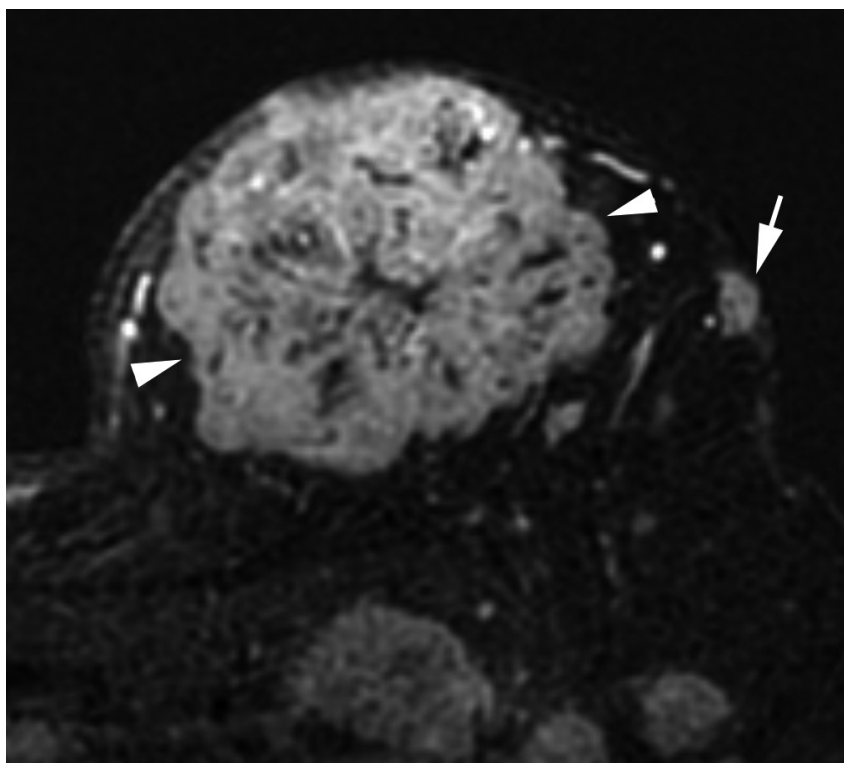

Fig. 3. T4b breast cancer. MRI shows primary breast cancer in left upper breast (arrowheads). Separate skin nodule is identified at left upper outer part, which qualifies as T4b (arrow). MRI = magnetic resonance imaging

\section{Lymph Nodes}

Unlike T categories, nodal staging uses separate clinical $\mathrm{N}(\mathrm{cN})$ and pathologic $\mathrm{N}(\mathrm{pN})$ categories. For the clinical evaluation of the node status, the 8th edition does not contain any significant changes from the 7 th edition (Table 4). Although the clinical stage can be determined without an imaging evaluation, imaging is valuable in assessing regional lymph node metastases. The method of confirmation of metastatic lymph nodes should be noted: $\mathrm{cN}$, confirmed by clinical findings; $\mathrm{cN}(\mathrm{f})$, confirmed by fineneedle aspiration or core biopsy; or $\mathrm{cN}(\mathrm{sn})$, confirmed by sentinel node biopsy. The regional lymph nodes occur in the ipsilateral axillary, ipsilateral internal mammary, and ipsilateral supraclavicular areas. The levels of axillary lymph nodes are defined using the pectoralis minor muscle as a landmark: level I lymph nodes are on the lateral border of the pectoralis minor muscle, level II nodes are between the medial and lateral borders of the pectoralis minor muscle, and level III nodes are on the medial border of pectoralis minor muscle. Imaging findings for metastatic axillary lymph nodes include loss of fatty hilum, eccentric cortical thickening, round shape, extranodal extension, and marked hypoechoic cortex on the ultrasound (10); round or irregular shape, increased density, or loss of fatty hilum on mammography (11); and loss of fatty hilum (12), round shape (13), and eccentric cortical thickening on $\operatorname{MRI}(13,14)$. The $\mathrm{CN} 1$ indicates metastases to one or more movable, ipsilateral, levels I and II axillary lymph nodes. The cN2a indicates metastases to fixed, ipsilateral, levels I and II axillary lymph nodes; $c N 2 b$ indicates metastases to ipsilateral internal mammary lymph nodes without evidence of axillary lymph node metastases. The cN3a indicates ipsilateral level III lymph nodes regardless of the status of levels I and II axillary lymph (Fig. 6); cN3b indicates 

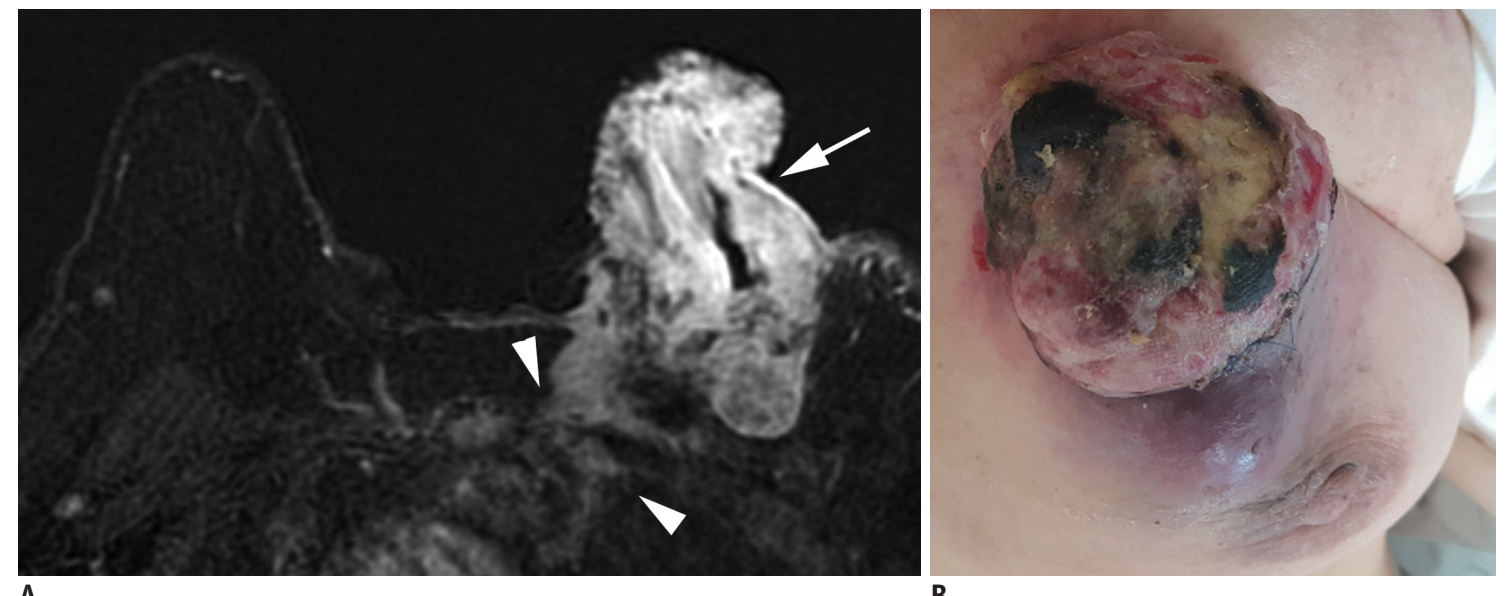

B

Fig. 4. T4c breast cancer.

A. MRI shows left breast cancer with skin ulceration (arrow) and rib extension (arrowheads). B. Physical examination shows ulceration extending to less than one third of breast, which does not meet definition of IBC. IBC = inflammatory breast cancer

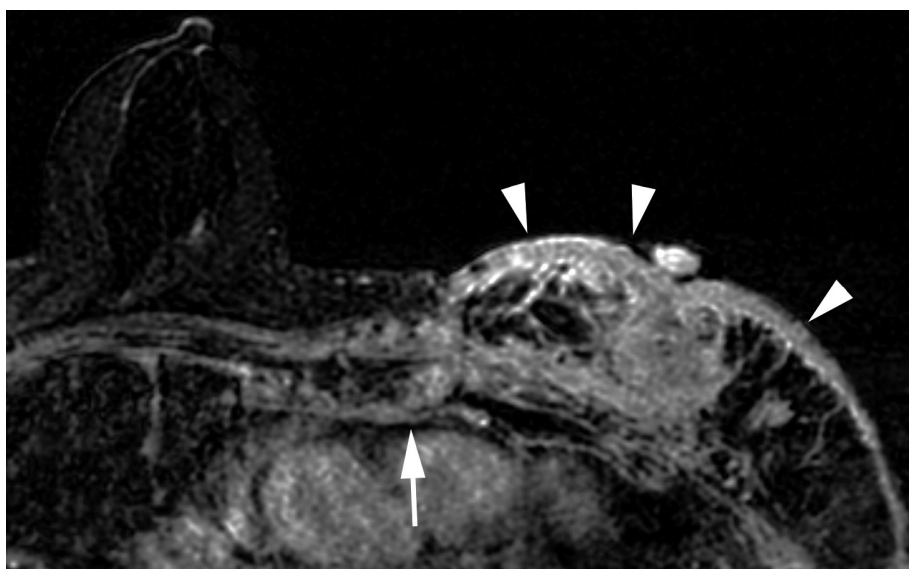

A

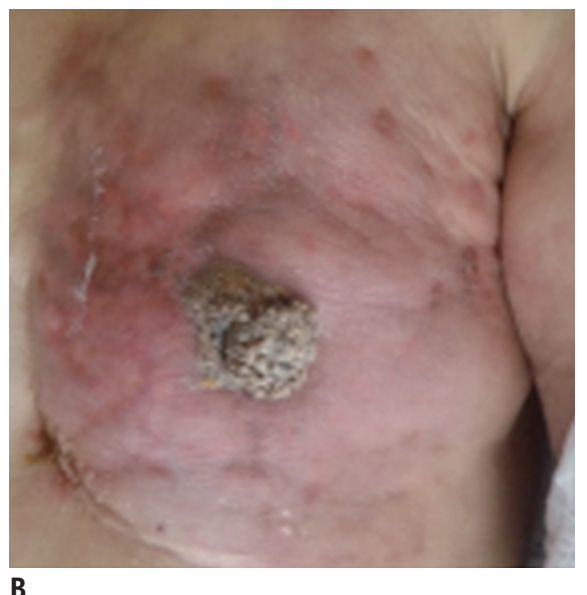

B

Fig. 5. Left IBC (T4d).

A. MRI shows diffuse skin enhancement (arrowheads) and chest wall extension (arrow). B. Physical examination of left breast shows erythema and peau d'orange (orange peel skin) appearance of skin, which meets definition of IBC.

\section{Table 4. Definition of Clinical Regional Lymph N Categories}

\begin{tabular}{|c|c|}
\hline Stage & Definition \\
\hline $\mathrm{cNX}$ & Regional lymph nodes cannot be assessed (for example, previously removed) \\
\hline $\mathrm{cNO}$ & No regional lymph node metastases \\
\hline $\mathrm{cN1}$ & Metastases to movable ipsilateral level I, II axillary lymph node(s) \\
\hline cN2 & $\begin{array}{l}\text { Metastases in ipsilateral level I, II axillary lymph nodes that are clinically fixed or matted; or in clinically detected } \\
\text { ipsilateral internal mammary nodes in absence of clinically evident axillary lymph node metastases }\end{array}$ \\
\hline $\mathrm{cN} 2 \mathrm{a}$ & Metastases in ipsilateral level I, II axillary lymph nodes fixed to one another (matted) or to other structures \\
\hline $\mathrm{cN} 2 \mathrm{~b}$ & $\begin{array}{l}\text { Metastases only in clinically detected ipsilateral internal mammary nodes and in absence of clinically evident level I, II } \\
\text { axillary lymph node metastases }\end{array}$ \\
\hline $\mathrm{cN3}$ & $\begin{array}{l}\text { Metastases in ipsilateral infraclavicular (level III axillary) lymph node(s) with or without level I, II axillary lymph node } \\
\text { involvement; or in clinically detected ipsilateral internal mammary lymph node(s) with clinically evident level I, II } \\
\text { axillary lymph node metastases; or metastases in ipsilateral supraclavicular lymph node(s) with or without axillary or } \\
\text { internal mammary lymph node involvement }\end{array}$ \\
\hline $\mathrm{cN3a}$ & Metastases in ipsilateral infraclavicular lymph node(s) \\
\hline cN3b & Metastases in ipsilateral internal mammary lymph node(s) and axillary lymph node(s) \\
\hline $\mathrm{cN} 3 \mathrm{c}$ & Metastases in ipsilateral supraclavicular lymph node(s) \\
\hline
\end{tabular}


both ipsilateral internal mammary and axillary lymph node metastases (Fig. 6); and $\mathrm{CN} 3 \mathrm{C}$ indicates ipsilateral supraclavicular lymph node metastases (Fig. 6).

The 8th edition clearly indicates that pathologic staging of lymph node metastases uses only the largest contiguous tumor deposit for pN. Pathologic classification is defined by the regions of lymph nodes involved and the number of ipsilateral axillary lymph node metastases (Table 5). The American College of Surgeons Oncology Group Z0011 trial sparked debates about whether an imaging evaluation of axillary lymph nodes should be performed $(15,16)$. Since patients with T1 or T2 tumors, undergoing only a sentinel node biopsy, did not have an inferior survival rate compared to those who received a complete axillary node dissection, some researchers argued that an imaging evaluation of axillae for early stage breast cancer was unnecessary (16). However, the axillary evaluation retained its importance in other studies $(17,18)$. An evaluation of the axillary lymph nodes should cover both levels I and II. When lymph node metastases are suspected, the level III internal mammary chain, and supraclavicular area should also be evaluated.

\section{Metastasis}

Stage M1 is designated when distant metastases are found, including contralateral lymph node metastases (Table 6). Metastases can be detected in various imaging studies. The 8th edition clarifies that pMO is not a valid category; benign biopsy of a suspicious lesion does not guarantee the absence of metastatic lesions elsewhere, and therefore, only cM0, cM1, and pM1 grades are used. The most common sites of breast cancer metastases are bone, lung, brain, and liver (19). Category M1 indicates stage IV disease regardless of $\mathrm{T}$ or $\mathrm{N}$ status and shows the poorest prognosis. For patients with stage I-IIB, systemic evaluation including bone scan, abdominal computed tomography (CT), or chest CT is only recommended when there are clinical signs, symptoms, or laboratory abnormalities suggesting metastases. For patients with a locally advanced disease, screening systemic

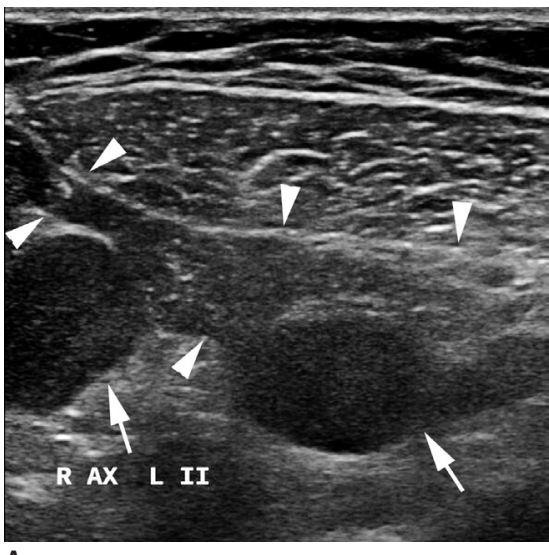

A

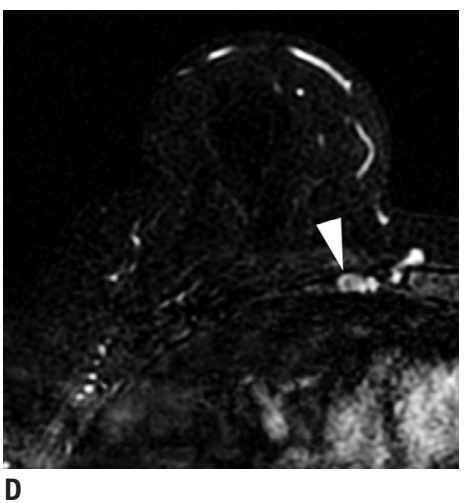

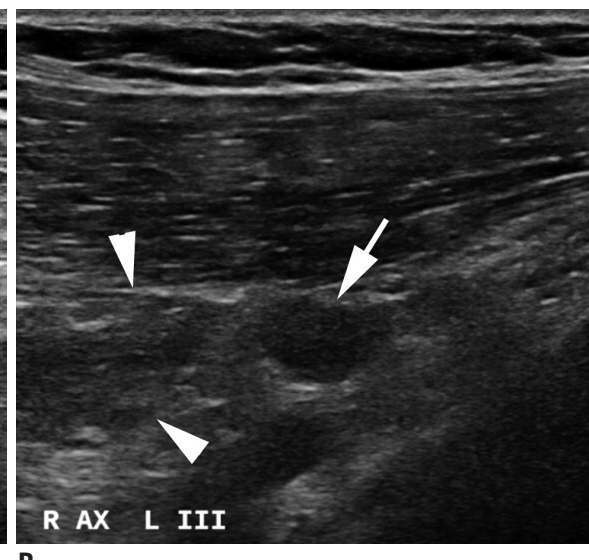

B

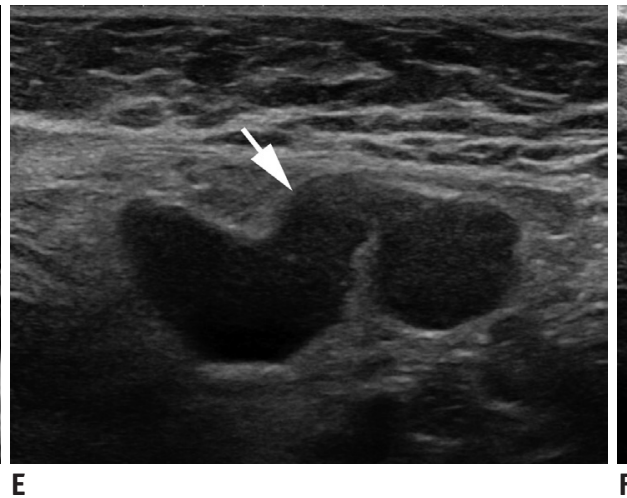

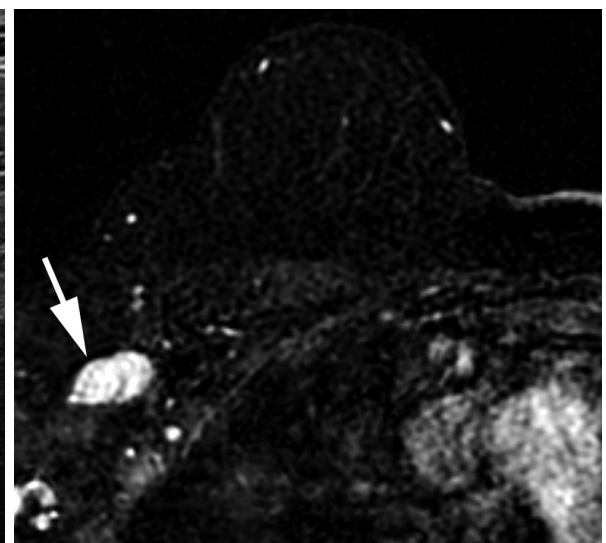

C

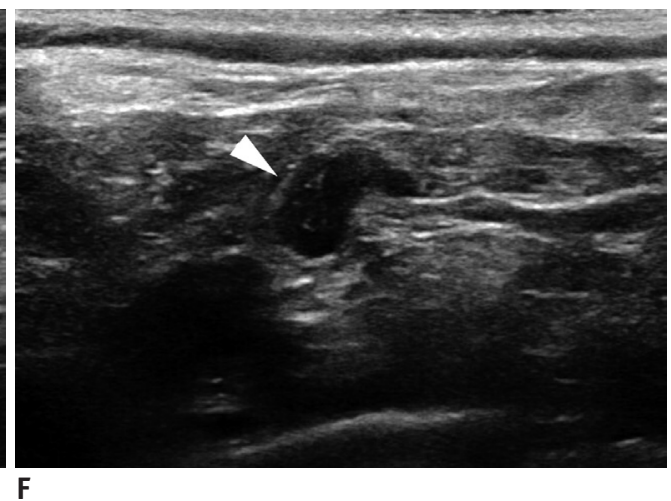

Fig. 6. cN3 category.

A, B. cN3a: Ultrasound images from right breast cancer case show enlarged hypoechoic lymph nodes with loss of fatty hilum not only in right axilla (A) level II (arrows), but also on (B) level III (arrow). Note pectoralis minor muscle (arrowheads), which is landmark for grouping axillary lymph nodes. C, D. cN3b: (C) MRI of case of cancer in right breast shows enlarged lymph nodes in right axilla (arrow). (D) Enlarged right internal mammary lymph node is also noted (arrowhead). E, F. cN3c: (E) Ultrasound of left breast cancer case shows enlarged lymph node in left axilla (arrow). (F) Enlarged left supraclavicular lymph node is also noted (arrowhead). AX = axilla 
Table 5. Definition of Pathologic Regional Lymph N Categories

\begin{tabular}{|c|c|}
\hline Stage & Definition \\
\hline $\mathrm{pNX}$ & Regional lymph nodes cannot be assessed (e.g., not removed for pathological study or previously removed) \\
\hline pNO & No regional lymph node metastasis identified or ITCs only \\
\hline pNO $(i+)$ & ITCs only (malignant cell clusters no larger than $0.2 \mathrm{~mm}$ ) in regional lymph node(s) \\
\hline pNO (mol+) & Positive molecular findings by reverse transcriptase-polymerase chain reaction; no ITCs detected \\
\hline pN1 & $\begin{array}{l}\text { Micrometastases; or metastases in 1-3 axillary lymph nodes; and/or clinically negative internal mammary lymph nodes } \\
\text { with micrometastases or macrometastases by sentinel lymph node biopsy }\end{array}$ \\
\hline pN1mi & Micrometastases (approximately 200 cells, larger than $0.2 \mathrm{~mm}$, but none larger than $2.0 \mathrm{~mm}$ ) \\
\hline $\mathrm{pN} 1 \mathrm{a}$ & Metastases in 1-3 axillary lymph nodes, at least one metastasis larger than $2.0 \mathrm{~mm}$ \\
\hline pN1b & Metastases in ipsilateral internal mammary sentinel lymph nodes, excluding ITCs \\
\hline $\mathrm{pN} 1 \mathrm{c}$ & pN1a and pN1b combined \\
\hline pN2 & $\begin{array}{l}\text { Metastases in 4-9 axillary lymph nodes; or positive ipsilateral internal mammary lymph nodes by imaging in absence } \\
\text { of axillary lymph node metastases }\end{array}$ \\
\hline $\mathrm{pN} 2 \mathrm{a}$ & Metastases in 4-9 axillary lymph nodes (at least one tumor deposit larger than $2.0 \mathrm{~mm}$ ) \\
\hline $\mathrm{pN} 2 \mathrm{~b}$ & $\begin{array}{l}\text { Metastases in clinically detected internal mammary lymph nodes with or without microscopic confirmation; } \\
\text { with pathologically negative axillary lymph nodes }\end{array}$ \\
\hline pN3 & $\begin{array}{l}\text { Metastases in } 10 \text { or more axillary lymph nodes; or in infraclavicular (level III axillary) lymph nodes; or positive } \\
\text { ipsilateral internal mammary lymph nodes by imaging in presence of one or more positive level I and II axillary lymph } \\
\text { nodes; or in more than } 3 \text { axillary lymph nodes and micrometastases or macrometastases by sentinel lymph node biopsy } \\
\text { in clinically negative ipsilateral internal mammary lymph nodes; or in ipsilateral supraclavicular lymph nodes }\end{array}$ \\
\hline pN3a & $\begin{array}{l}\text { Metastases in } 10 \text { or more axillary lymph nodes (at least one tumor deposit larger than } 2.0 \mathrm{~mm} \text { ); or metastases to } \\
\text { infraclavicular (level III axillary lymph) nodes }\end{array}$ \\
\hline pN3b & pN1a or pN2a in presence of $c N 2 b$ (positive internal mammary lymph nodes by imaging); or pN2a in presence of pN1b \\
\hline $\mathrm{pN} 3 \mathrm{c}$ & Metastases in ipsilateral supraclavicular lymph nodes \\
\hline
\end{tabular}

ITCs $=$ isolated tumor cells

Table 6. Definition of Distant M Categories

\begin{tabular}{|c|c|}
\hline Stage & Definition \\
\hline MO & No clinical or radiographic evidence of distant metastases \\
\hline cMO (i+) & $\begin{array}{l}\text { No clinical or radiographic evidence of distant metastases, but deposits of molecularly or microscopically detected tumor cells } \\
\text { in circulating blood, bone marrow, or other non-regional nodal tissue that are no larger than } 0.2 \mathrm{~mm} \text { in patient without } \\
\text { symptoms or signs of metastases }\end{array}$ \\
\hline CM1 & Distant metastases detected by clinical and radiographic means \\
\hline pM1 & Any histologically proven metastases in distant organs; or if in non-regional nodes, metastases greater than $0.2 \mathrm{~mm}$ \\
\hline
\end{tabular}

evaluation using positron emission tomography can be performed (Fig. 7) (20).

\section{Post-Neoadjuvant Therapy Staging}

Neoadjuvant therapy is widely performed in locally advanced breast cancer, IBC, and even operable breast cancer (21). After neoadjuvant therapy, the y prefix is used. The ycT is determined by measuring the largest single focus of the residual tumor by examination or imaging (Fig. 8). When there is no residual disease, it is classified as ycT0. IBC (cT4d) retains the same classification stage even if complete resolution of the tumor is observed. The $y c \mathrm{~N}$ is determined by clinical or radiographic findings of residual lymph nodes. Pre-treatment M1 disease is designated as M1 throughout treatment. When surgery is performed after neoadjuvant chemotherapy, the yp classification is applied. The response to neoadjuvant chemotherapy is evaluated as complete response (CR), partial response, or no response. CR is designated to the tumor when residual invasive cancer is not found in the breast tissue and lymph nodes, clinically or pathologically (Fig. 9). The presence of in situ cancer constitutes a pathologic CR. Partial response is defined as a decrease in the $\mathrm{T}$ or $\mathrm{N}$ category without any evidence of increase in either the $\mathrm{T}$ or $\mathrm{N}$ category. No change or an increase in the $\mathrm{T}$ or $\mathrm{N}$ category is defined as no response. 


\section{Adoption of the Prognostic Stage}

For the 8th edition, the AJCC committee created the prognostic staging protocol. This integrates biomarkers into the TNM staging system, making use of the results from large cohort studies, which shows that not only pathologic stage, but also different biomarkers could affect survival $(1,22)$. The biomarkers indicate tumor grade, hormone receptor status, and HER2. Multigene panel status is also incorporated into the staging system in limited sub-groups. The 8th edition defines clinical and pathologic prognostic stages that combine anatomic staging with tumor grade,

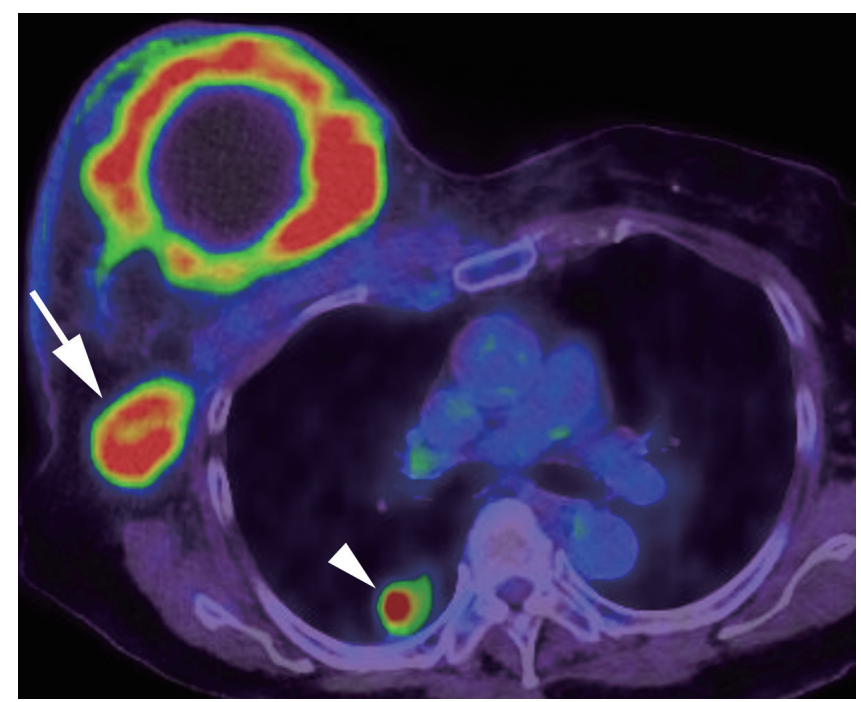

Fig. 7. Right breast cancer with lung metastasis (M1). 0n

positron emission tomography-computed tomography, $10-\mathrm{cm}$ cancerous mass is seen in right breast and multiple FDG uptakes are seen in right axillary lymph nodes (arrow); there are lung nodules with FDG uptake, suggesting lung metastasis (arrowhead). FDG = fludeoxyglucose, $M=$ metastasis

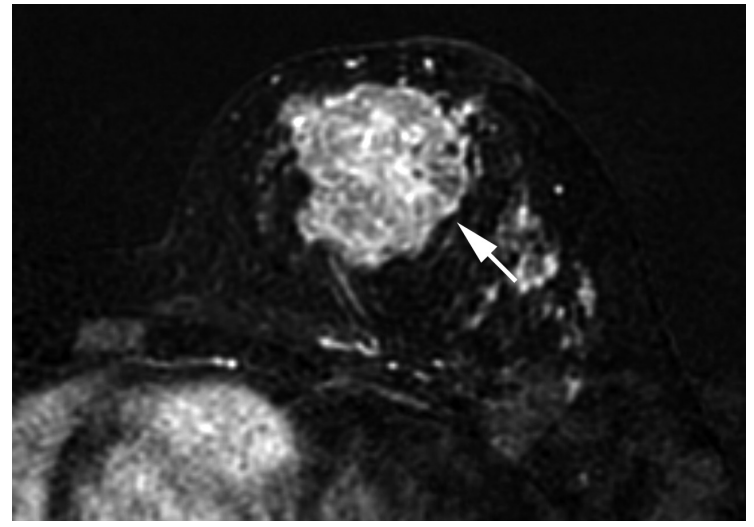

A hormone receptor status, and HER2 status (Figs. 10, 11).

\section{Tumor Grade}

Tumor grade is an important prognostic factor independent of the tumor size and number of positive lymph nodes (23). Tumor grade reflects tumor differentiation with worse prognosis observed in tumors with a high histologic grade or poor differentiation, than those with a low grade or well-differentiated (Fig. 12) (24). A modified ScarffBloom-Richardson system measuring tubules (glands), nuclear pleomorphism, and mitotic counts is used to evaluate the tumor grade $(24,25)$.

\section{Hormone Receptor and HER2 Expression}

Evaluating the expression of estrogen receptors (ERs) and progesterone receptors (PRs) in breast cancer is important, because selective ER modulators slow the progression of ER-positive and PR-positive tumors $(26,27)$. Furthermore, breast cancer is related to several oncogenes including HER2. The presence of HER2 is associated with a poor prognosis in untreated patients (28-30). However, HER2 targeting agents (trastuzumab) improve the prognosis for patients with HER2 positive tumors $(31,32)$. A high Ki-67 level reflects rapidly dividing tumor cells, although there is no universal cut-off for measuring Ki-67 levels $(33,34)$. According to the ER/PR and HER2 status and with additional information about Ki-67, the 8th edition identifies four subtypes: luminal $A$ (hormone receptor-positive, HER2negative, low Ki-67), luminal B (hormone receptorpositive, HER2-negative, high Ki-67), HER2 (HER2-positive regardless of the hormone receptor status), and basal (both hormone receptor and HER2 negative) $(35,36)$. The luminal

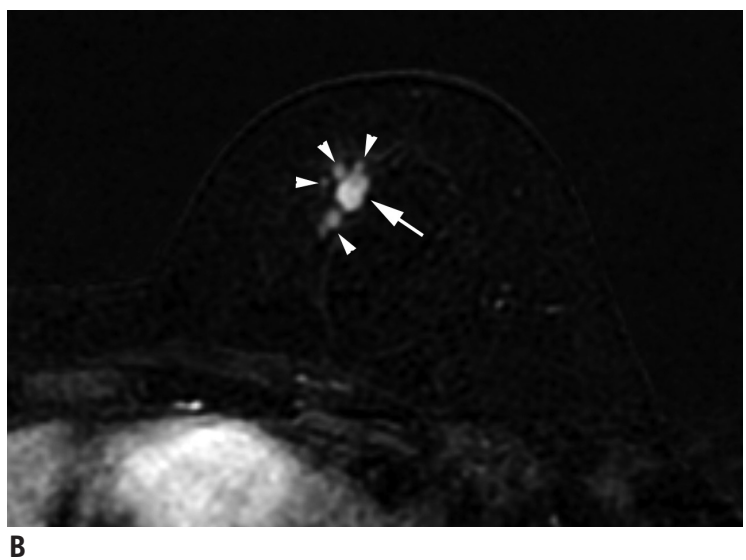

Fig. 8. Size measurement after neoadjuvant chemotherapy.

A. Initial MRI shows 4.3-cm irregular breast cancer in left breast (T2) (arrow). B. After neoadjuvant chemotherapy, cancer reduced to multiple small masses (arrowheads); largest one measures $10 \mathrm{~mm}$ (arrow). Therefore, post treatment T category is ycT1b (m). 

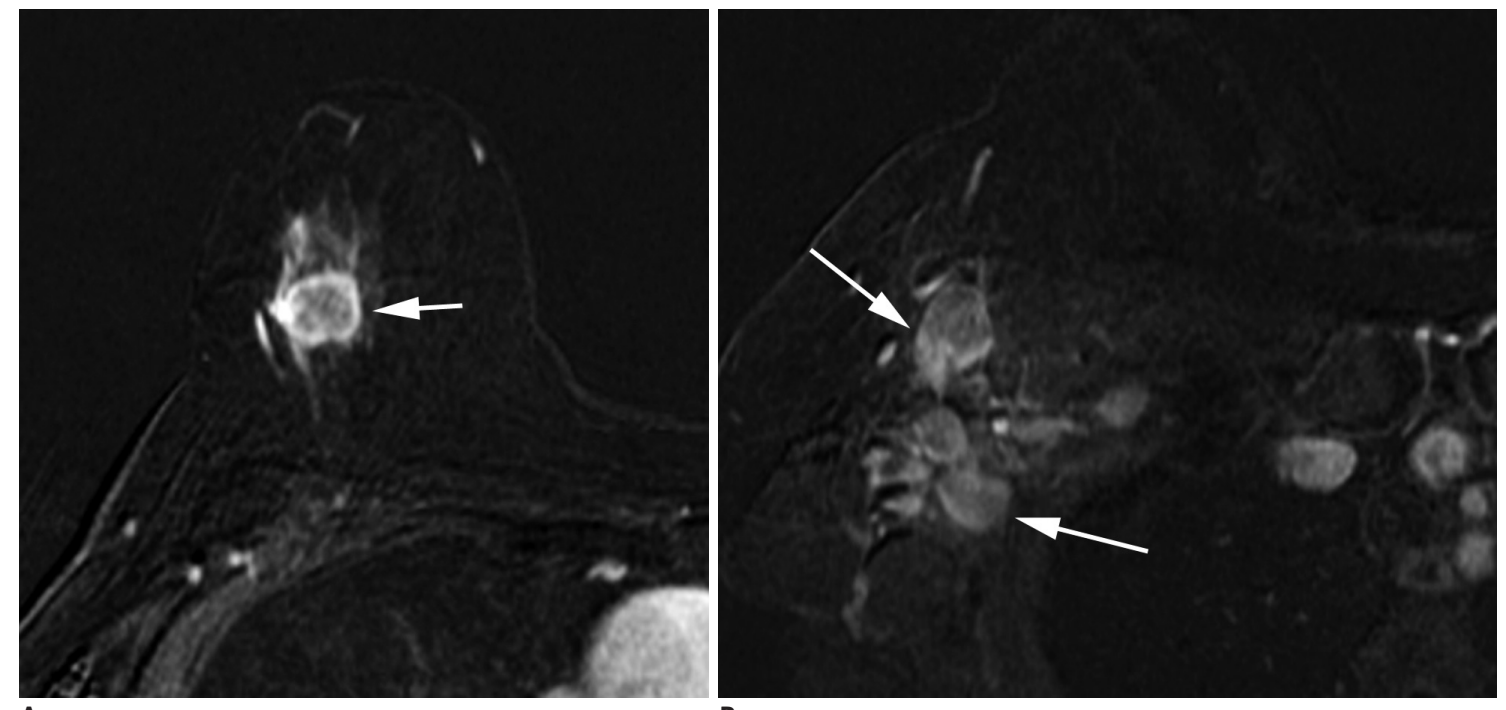

A

B
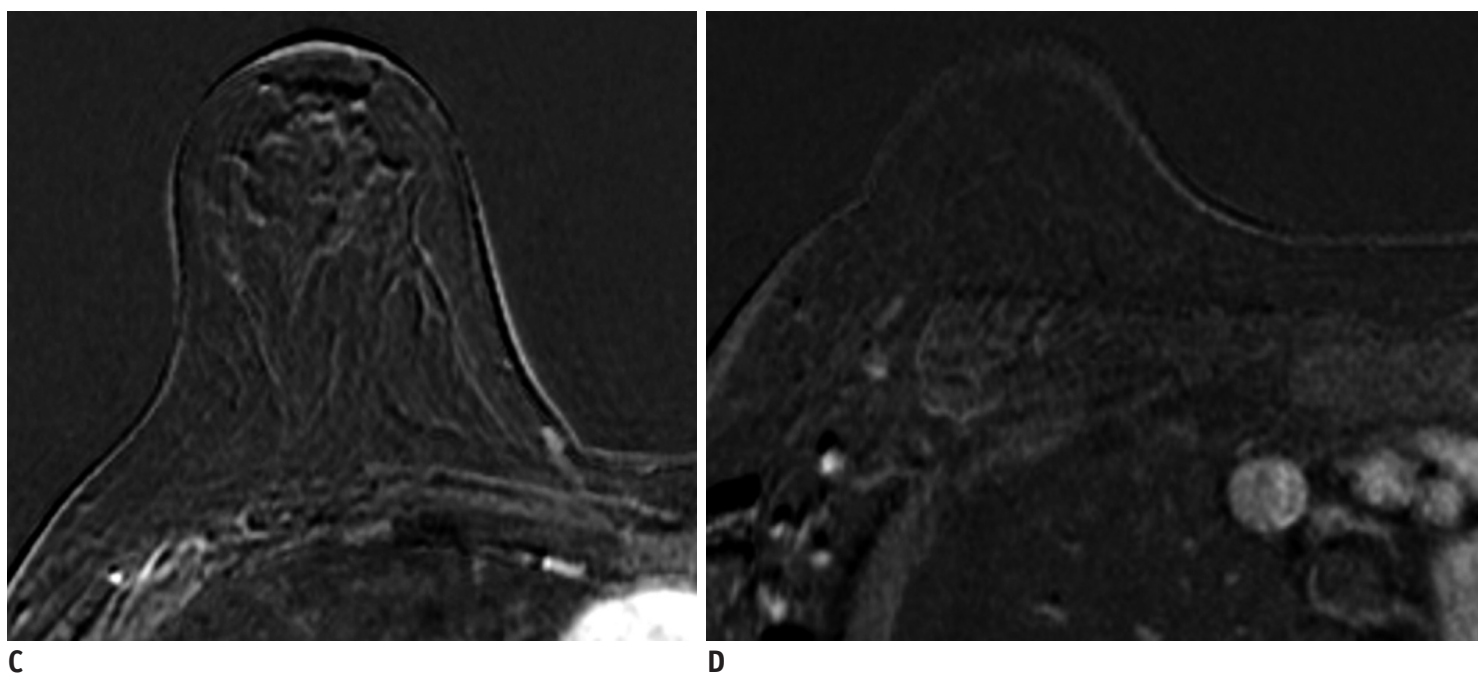

Fig. 9. Patient with cancer in right breast with MRI before (A, B) and after neoadjuvant chemotherapy (C, D). A. Initial MRI shows 2.2-cm right breast cancer (arrow). B. Ipsilateral matted axillary lymph node enlargement is noted (arrows). Initial stage is T2N2aM0. C. After neoadjuvant chemotherapy, there is no residual mass. D. Axillary lymph nodes have disappeared, which suggests clinical CR (ycTONOM0). Histopathologic evaluation shows absence of invasive carcinoma in breast and lymph nodes, indicating pathologic CR (ypTONOM0). CR $=$ complete response

A type has the best prognosis, with excellent response to endocrine therapies. The luminal $B$ type is less responsive to endocrine therapies and has worse prognosis than the luminal A type. The HER2 type responds to HER2 targeting agents and proper treatment improves the prognosis. The basal type, also known as a triple-negative tumor, has the worst prognosis (Fig. 13).

\section{Multigene Panel Status}

Multigene panel tests measure the expression levels of a large number of genes in breast cancer tissue, and several panels are available for the same. Among them,
Oncotype DX has the best available evidence, and thus, it is the one incorporated into the 8th edition (37-41). Based on this evidence, patients with hormone receptorpositive, HER2-negative, and lymph node-negative tumors with a recurrence score less than 11 on the Oncotype DX, are placed into stage I (T1a-T1bNOM0) regardless of $\mathrm{T}$ size. Other multigene panels, including Mammaprint (42), EndoPredict $(43,44), \operatorname{PAM} 50(45,46)$, and the Breast Cancer Index $(47,48)$ have shown results similar to those of Oncotype Dx, but at present they are not included in the TNM staging system. 


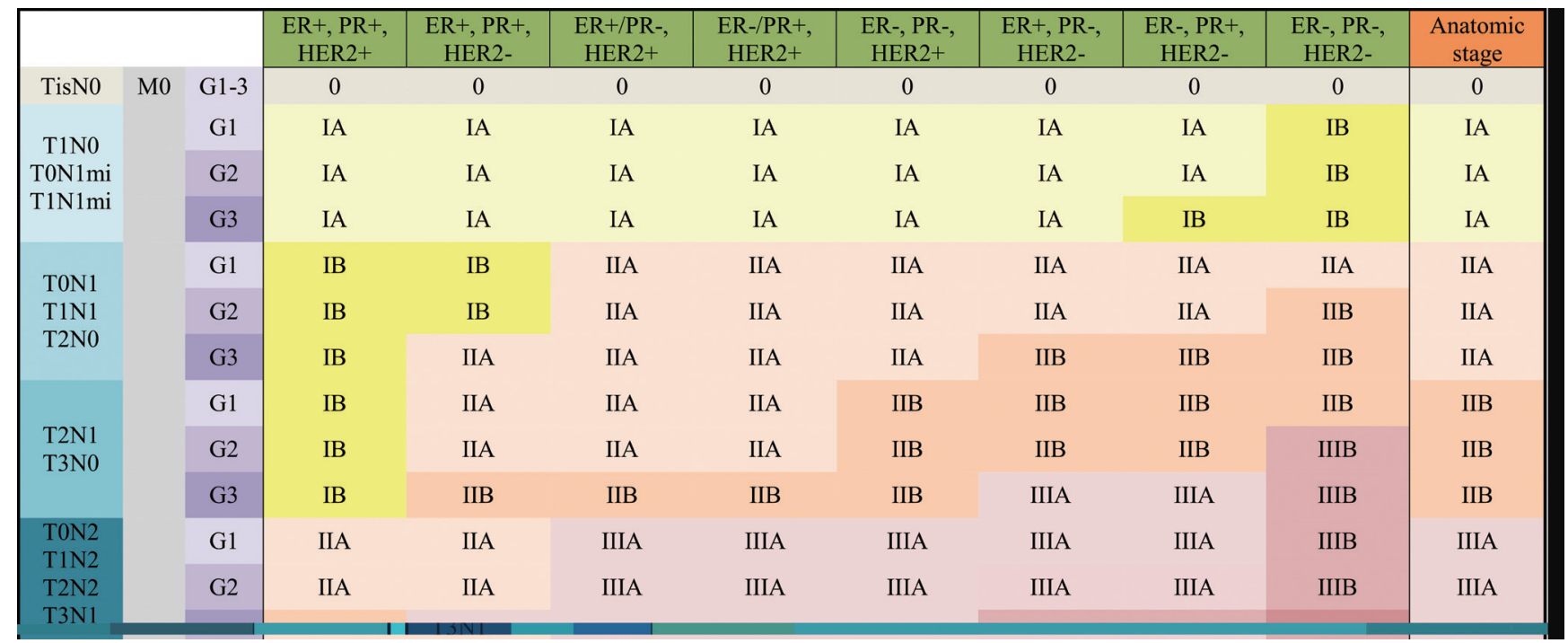

Fig. 10. Clinical Prognostic Stage is assigned to all patients regardless of type of therapy given. ER- = estrogen receptor-negative, $\mathrm{ER}+=\mathrm{ER}$-positive, $\mathrm{G}=$ grade, $H E R 2-=H E R 2$ negative, $H E R 2+=H E R 2$-positive, $\mathrm{mi}=$ micrometastasis, $\mathrm{PR}-=$ progesterone receptor-negative, $\mathrm{PR}+=$ PR-positive, Tis $=$ in situ

\begin{tabular}{|c|c|c|c|c|c|c|c|c|c|c|c|}
\hline & & & $\begin{array}{c}\text { ER+, PR+, } \\
\text { HER2 }+\end{array}$ & $\begin{array}{c}\text { ER+, PR+, } \\
\text { HER2- }\end{array}$ & $\begin{array}{c}\text { ER+/PR-, } \\
\text { HER2+ }\end{array}$ & $\begin{array}{c}\text { ER-/PR+, } \\
\text { HER2+ }\end{array}$ & $\begin{array}{c}\text { ER-, PR-, } \\
\text { HER2 }+\end{array}$ & $\begin{array}{c}\text { ER+, PR-, } \\
\text { HER2- }\end{array}$ & $\begin{array}{c}\text { ER-, PR+, } \\
\text { HER2- }\end{array}$ & $\begin{array}{c}\text { ER-, PR-, } \\
\text { HER2- }\end{array}$ & $\begin{array}{c}\text { Anatomic } \\
\text { stage }\end{array}$ \\
\hline \multirow{4}{*}{$\begin{array}{c}\text { TisN0 } \\
\text { T1N0 } \\
\text { T0N1mi } \\
\text { T1N1mi }\end{array}$} & \multirow[t]{16}{*}{ M0 } & G1-3 & 0 & 0 & 0 & 0 & 0 & 0 & 0 & 0 & 0 \\
\hline & & G1 & IA & IA & IA & IA & IA & IA & IA & IA & IA \\
\hline & & G2 & IA & IA & IA & IA & IA & IA & IA & IB & IA \\
\hline & & G3 & IA & IA & IA & IA & IA & IA & IA & IB & IA \\
\hline \multirow{3}{*}{$\begin{array}{l}\text { T0N1 } \\
\text { T1N1 } \\
\text { T2N0 }\end{array}$} & & G1 & IA & IA & IB & IB & IIA & IB & IB & IIA & IIA \\
\hline & & G2 & IA & IA & IB & IB & IIA & IIA & IIA & IIA & IIA \\
\hline & & G3 & IA & IB & IIA & IIA & IIA & IIA & IIA & IIA & IIA \\
\hline \multirow{3}{*}{$\begin{array}{l}\text { T2N1 } \\
\text { T3N0 }\end{array}$} & & G1 & IA & IA & IIB & IIB & IIB & IIB & IIB & IIB & IIB \\
\hline & & G2 & IB & IB & IIB & IIB & IIB & IIB & IIB & IIB & IIB \\
\hline & & G3 & IB & IIA & IIB & IIB & IIB & IIB & IIB & IIIA & IIB \\
\hline \multirow{3}{*}{$\begin{array}{l}\text { T0N2 } \\
\text { T1N2 } \\
\text { T2N2 } \\
\text { T3N1 } \\
\text { T3N2 }\end{array}$} & & G1 & IB & IB & IIIA & IIIA & IIIA & IIIA & IIIA & IIIA & IIIA \\
\hline & & G2 & IB & IB & IIIA & IIIA & IIIA & IIIA & IIIA & IIIB & IIIA \\
\hline & & G3 & IIA & IIB & IIIA & IIIA & IIIA & IIIA & IIIA & IIIC & IIIA \\
\hline \multirow{3}{*}{$\begin{array}{l}\text { T4N0 } \\
\text { T4N1 } \\
\text { T4N2 } \\
\text { AnyN3 }\end{array}$} & & G1 & IIIA & IIIA & IIIB & IIIB & IIIB & IIIB & IIIB & IIIB & IIIB \\
\hline & & G2 & IIIA & IIIA & IIIB & IIIB & IIIB & IIIB & IIIB & IIIC & IIIB \\
\hline & & G3 & IIIB & IIIB & IIIB & IIIB & IIIB & IIIC & IIIC & IIIC & IIIB \\
\hline Any & M1 & Any & IV & IV & IV & IV & IV & IV & IV & IV & IV \\
\hline
\end{tabular}

Fig. 11. Pathologic Prognostic Stage is assigned to patients who received surgery as initial treatment. Additionally, pT1, pT2, pN0, M0, ER+, and HER2- cancers are assigned as Pathologic Prognostic Stage group IA when Oncotype DX recurrence score is less than 11.

\section{Prognostic Stage Groups}

Two large cohorts, the MD Anderson Cancer Center study (22) and the National Cancer Data Base (NCDB) study (David JW, unpublished data), were analyzed to incorporate biomarkers into prognostic staging (1). The first study identified risk profiles using not only pathologic stages, but also high tumor grade, ER-negative status, and HER2negative status $(22,49)$. The second unpublished study used the NCDB to reveal that patients with triple-negative tumors, regardless of grade, should be categorized at least one stage higher than other sub-types (David JW, unpublished data). Grade-3 tumors, HER2-negative, and ER-negative or PR-negative tumors should also have a higher stage (Fig. 14). Patients whose tumors expressed both ER and PR, with or without HER2 over-expression, had better survival (Fig. 15). Based on that study, the 8th edition defines Clinical and Pathologic Prognostic Stages that combine anatomic staging with tumor grade, 


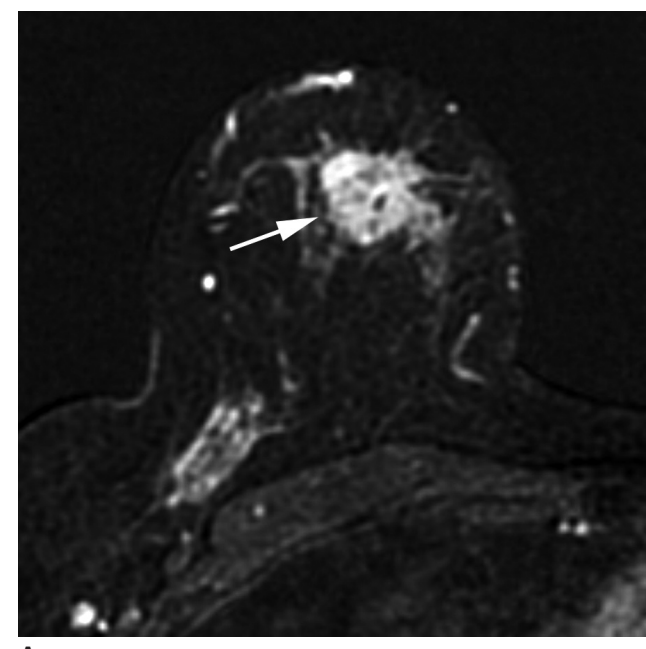

A

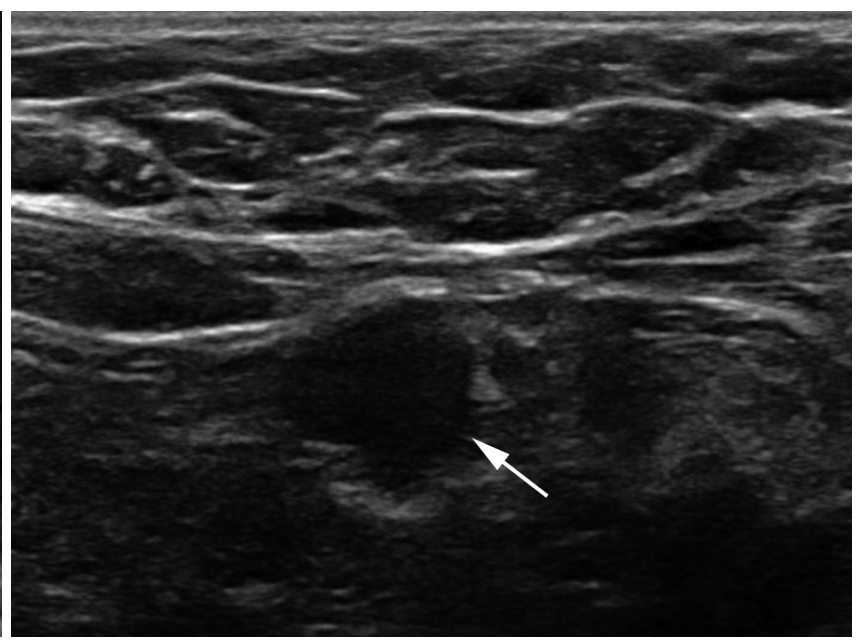

B

Fig. 12. Right breast cancer with low histologic grade.

A. MRI demonstrates breast cancer measuring $2.3 \mathrm{~cm}$ in upper breast (arrow). B. Ultrasound shows enlarged, right axillary lymph node with eccentric cortical thickening (arrow). After partial mastectomy, cancer measures $2.5 \mathrm{~cm}$ with two level-I lymph node metastases. Cancer is ER+/ PR+ and HER2-. Histologic grade is 1, and anatomic stage is IIB (T2N1M0). However, due to low histologic grade and biomarker status, Clinical Prognostic Stage is IIA and Pathologic Prognostic Stage is IA.

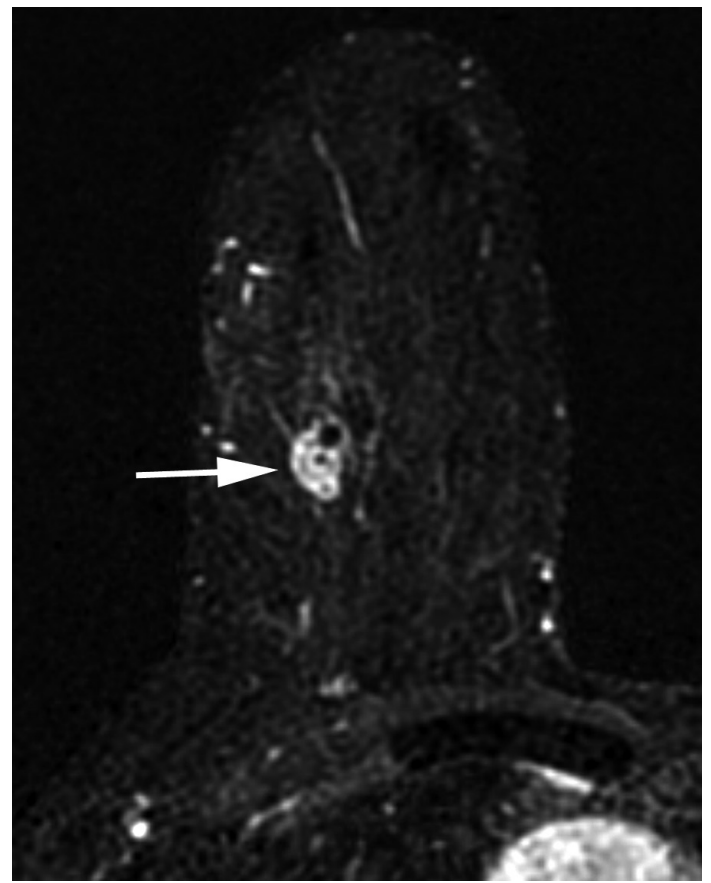

Fig. 13. cT1NOMO cancer. MRI shows that cancer measures $1.3 \mathrm{~cm}$ (arrow). There is no suspicious lymph node enlargement. Pathology shows $0.9-\mathrm{cm}$ grade-2 carcinoma, but no hormone receptor or HER2 overexpression is noted. Therefore, anatomic stage is IA (T1NOM0), but it is triple negative cancer; thus, Clinical and Pathologic Prognostic Stages are higher, IB.

hormone receptor (ER/PR) status, and HER2 status. A Clinical Prognostic Stage is assigned to all patients regardless of the type of therapy they received (Fig. 10). A Pathologic Prognostic Stage is assigned to patients

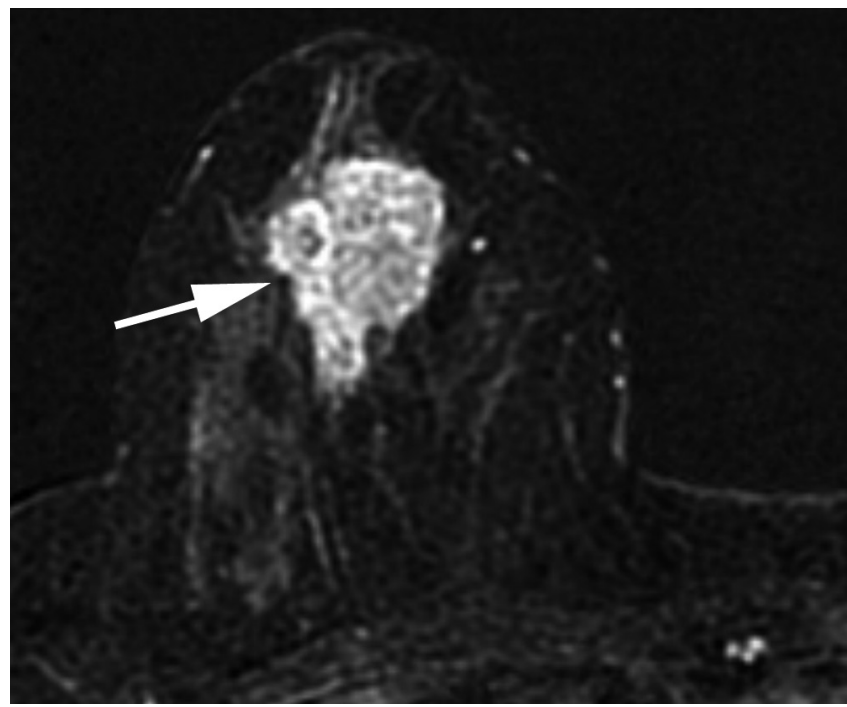

Fig. 14. cT2NOMO cancer. MRI shows 3.7-cm enhancing cancer (arrow). No axillary metastasis is found. Anatomic stage is IIA. Tumor grade is 3, and hormone receptor and HER2 expressions are negative. This tumor has high histologic grade and is triple-negative; therefore, Clinical Prognostic Stage is higher, IIB.

who receive surgery as the initial treatment, excluding patients who receive neoadjuvant chemotherapy (Fig. 11). Using the NCDB data, three-year overall survival rate was calculated with the inclusion of grade, hormone receptor, and HER2 status. These results were compared with the 7th edition, and downstaging or upstaging was performed for the 8th edition. Additionally, pT1-T2, pNO, M0, ERpositive, and HER2-negative cancers were assigned as Pathologic Prognostic Stage group IA, when the Oncotype 

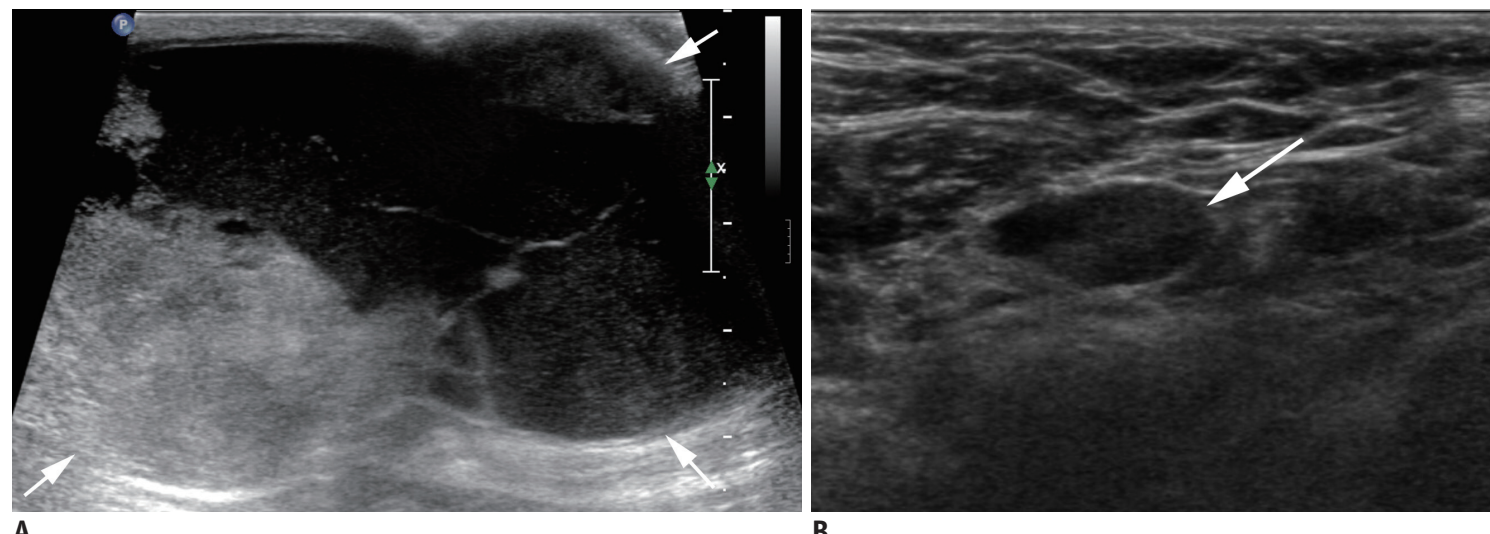

A

Fig. 15. cT3N1MO cancer downgraded by prognostic stage.

A. Ultrasound image indicates complex cystic and solid mass in left lower outer breast (arrows). B. Left axillary ultrasound image shows cortically thickened lymph node (arrow). Anatomic stage is IIIA. Tumor grade is 1, ER and PR expression are found, and HER2 shows no overexpression; therefore, Clinical Prognostic Stage is IIA, and Pathologic Prognostic Stage is IB.

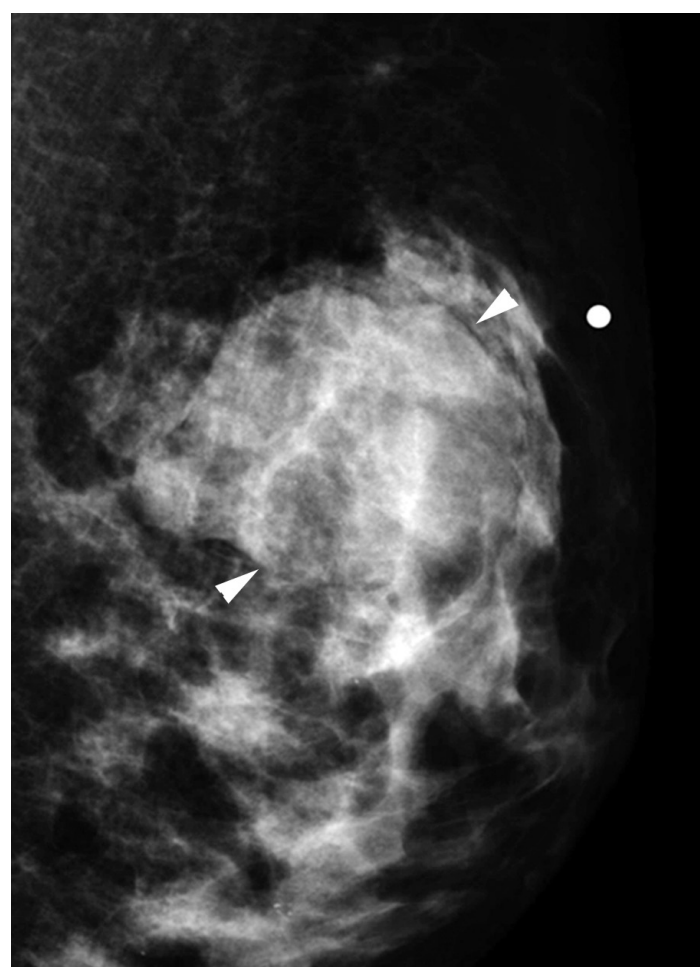

Fig. 16. cT2NOMO cancer. Mediolateral oblique mammographic view demonstrates mass in left upper outer breast (arrowheads). Lymph nodes are not enlarged. Anatomic stage is IIA. Tumor is ER expression positive, HER2 shows no overexpression, and Oncotype Dx recurrence score is 5; therefore, Pathologic Prognostic Stage is IA.

Dx recurrence score was less than 11 (Fig. 16).

\section{CONCLUSION}

In the 8th AJCC staging system of breast cancer, anatomic staging is maintained and the traditional role of radiology remains important. Anatomic staging is still the main system when immunohistochemical examinations are unavailable. However, radiologists should understand the importance of biomarkers in breast cancer staging. Different prognostic stages are assigned to tumors with the same anatomic stage depending on the histologic grade, hormone receptor status, HER2 status, and multigene panels. Different prognostic stages will call for different therapies for breast cancers with the same anatomic stage; therefore, radiologists' role in evaluating tumor response after appropriate therapies is also important.

\section{Conflicts of Interest}

The authors have no financial conflicts of interest.

\section{ORCID}

Min Jung Kim

https://orcid.org/0000-0003-4949-1237

Jieun Koh

https://orcid.org/0000-0002-5290-6248

\section{REFERENCES}

1. Gabriel NH, James LC, Carl JD, Stephen BE, Elizabeth AM, Hope SR, et al. Breast. In: Mahul BA, ed. American Joint Committee on Cancer (AJCC). AJCC cancer staging manual, 8th ed. New York, NY: Springer, 2017:589-628

2. Prat A, Pineda E, Adamo B, Galván P, Fernández A, Gaba L, et al. Clinical implications of the intrinsic molecular subtypes of breast cancer. Breast 2015;24 Suppl 2:S26-S35

3. Rezo A, Dahlstrom J, Shadbolt B, Rodins K, Zhang Y, Davis AJ; ACT \& SENSW BCTG. Tumor size and survival in multicentric and multifocal breast cancer. Breast 2011;20:259-263

4. Morris EA, Schwartz LH, Drotman MB, Kim SJ, Tan LK, 
Liberman L, et al. Evaluation of pectoralis major muscle in patients with posterior breast tumors on breast MR images: early experience. Radiology 2000;214:67-72

5. Lee EJ, Han SH, Kang BJ, Kim SH. Imaging and pathologic characterization of the skin thickening or enhancement under the breast MRI. Investig Magn Reson Imaging 2016;20:9-26

6. Chang S, Parker SL, Pham T, Buzdar AU, Hursting SD. Inflammatory breast carcinoma incidence and survival: the surveillance, epidemiology, and end results program of the National Cancer Institute, 1975-1992. Cancer 1998;82:23662372

7. Levine PH, Steinhorn SC, Ries LG, Aron JL. Inflammatory breast cancer: the experience of the surveillance, epidemiology, and end results (SEER) program. J Natl Cancer Inst 1985;74:291-297

8. Yang WT, Le-Petross HT, Macapinlac H, Carkaci S, GonzalezAngulo AM, Dawood S, et al. Inflammatory breast cancer: PET/CT, MRI, mammography, and sonography findings. Breast Cancer Res Treat 2008;109:417-426

9. Le-Petross HT, Cristofanilli M, Carkaci S, Krishnamurthy S, Jackson EF, Harrell RK, et al. MRI features of inflammatory breast cancer. AJR Am J Roentgenol 2011;197:W769-W776

10. Alvarez S, Añorbe E, Alcorta P, López F, Alonso I, Cortés J. Role of sonography in the diagnosis of axillary lymph node metastases in breast cancer: a systematic review. AJR Am J Roentgenol 2006;186:1342-1348

11. Patel T, Given-Wilson RM, Thomas V. The clinical importance of axillary lymphadenopathy detected on screening mammography: revisited. Clin Radiol 2005;60:64-71

12. Mortellaro VE, Marshall J, Singer L, Hochwald SN, Chang M, Copeland EM, et al. Magnetic resonance imaging for axillary staging in patients with breast cancer. J Magn Reson Imaging 2009;30:309-312

13. Valente SA, Levine GM, Silverstein MJ, Rayhanabad JA, WengGrumley JG, Ji L, et al. Accuracy of predicting axillary lymph node positivity by physical examination, mammography, ultrasonography, and magnetic resonance imaging. Ann Surg Oncol 2012;19:1825-1830

14. Yoshimura G, Sakurai T, Oura S, Suzuma T, Tamaki T, Umemura $\mathrm{T}$, et al. Evaluation of axillary lymph node status in breast cancer with MRI. Breast Cancer 1999;6:249-258

15. Giuliano AE, McCall L, Beitsch P, Whitworth PW, Blumencranz P, Leitch AM, et al. Locoregional recurrence after sentinel lymph node dissection with or without axillary dissection in patients with sentinel lymph node metastases: the American College of Surgeons Oncology Group Z0011 randomized trial. Ann Surg 2010;252:426-432; discussion 432-433

16. Humphrey KL, Saksena MA, Freer PE, Smith BL, Rafferty EA. To do or not to do: axillary nodal evaluation after ACOSOG Z0011 trial. Radiographics 2014;34:1807-1816

17. Verheuvel NC, van den Hoven I, Ooms HW, Voogd AC, Roumen $\mathrm{RM}$. The role of ultrasound-guided lymph node biopsy in axillary staging of invasive breast cancer in the post-ACOSOG Z0011 trial era. Ann Surg Oncol 2015;22:409-415
18. Farrell TP, Adams NC, Stenson M, Carroll PA, Griffin M, Connolly EM, et al. The Z0011 trial: is this the end of axillary ultrasound in the pre-operative assessment of breast cancer patients? Eur Radiol 2015;25:2682-2687

19. Patanaphan V, Salazar OM, Risco R. Breast cancer: metastatic patterns and their prognosis. South Med J 1988;81:1109-1112

20. Aebi S, Davidson T, Gruber G, Castiglione M; ESM0 Guidelines Working Group. Primary breast cancer: ESMO Clinical Practice Guidelines for diagnosis, treatment and follow-up. Ann Oncol 2010;21 Suppl 5:v9-v14

21. Rapoport BL, Demetriou GS, Moodley SD, Benn CA. When and how do I use neoadjuvant chemotherapy for breast cancer? Curr Treat Options Oncol 2014;15:86-98

22. Yi M, Mittendorf EA, Cormier JN, Buchholz TA, Bilimoria K, Sahin $A A$, et al. Novel staging system for predicting diseasespecific survival in patients with breast cancer treated with surgery as the first intervention: time to modify the current American Joint Committee on Cancer staging system. J Clin Oncol 2011;29:4654-4661

23. Schwartz AM, Henson DE, Chen D, Rajamarthandan S. Histologic grade remains a prognostic factor for breast cancer regardless of the number of positive lymph nodes and tumor size: a study of 161708 cases of breast cancer from the SEER Program. Arch Pathol Lab Med 2014;138:1048-1052

24. Elston CW, Ellis IO. Pathological prognostic factors in breast cancer. I. The value of histological grade in breast cancer: experience from a large study with long-term follow-up. Histopathology 1991;19:403-410

25. Elston EW, Ellis IO. Method for grading breast cancer. J Clin Pathol 1993;46:189-190

26. Early Breast Cancer Trialists' Collaborative Group (EBCTCG), Davies C, Godwin J, Gray R, Clarke M, Cutter D, et al. Relevance of breast cancer hormone receptors and other factors to the efficacy of adjuvant tamoxifen: patient-level meta-analysis of randomised trials. Lancet 2011;378:771-784

27. Barnes DM, Harris WH, Smith P, Millis RR, Rubens RD. Immunohistochemical determination of oestrogen receptor: comparison of different methods of assessment of staining and correlation with clinical outcome of breast cancer patients. Br J Cancer 1996;74:1445-1451

28. Slamon DJ, Clark GM, Wong SG, Levin WJ, Ullrich A, McGuire WL. Human breast cancer: correlation of relapse and survival with amplification of the HER-2/neu oncogene. Science 1987;235:177-182

29. Ross JS, Slodkowska EA, Symmans WF, Pusztai L, Ravdin PM, Hortobagyi GN. The HER-2 receptor and breast cancer: ten years of targeted anti-HER-2 therapy and personalized medicine. Oncologist 2009;14:320-368

30. Rosenthal SI, Depowski PL, Sheehan CE, Ross JS. Comparison of HER-2/neu oncogene amplification detected by fluorescence in situ hybridization in lobular and ductal breast cancer. Appl Immunohistochem Mol Morphol 2002;10:40-46

31. Slamon D, Eiermann W, Robert N, Pienkowski T, Martin M, Press $M$, et al.; Breast Cancer International Research Group. 
Adjuvant trastuzumab in HER2-positive breast cancer. $N$ Engl J Med 2011;365:1273-1283

32. Moasser MM, Krop IE. The evolving landscape of HER2 targeting in breast cancer. JAMA Oncol 2015;1:1154-1161

33. Gerdes J, Schwab U, Lemke H, Stein H. Production of a mouse monoclonal antibody reactive with a human nuclear antigen associated with cell proliferation. Int J Cancer 1983;31:13-20

34. Coates AS, Winer EP, Goldhirsch A, Gelber RD, Gnant M, Piccart-Gebhart M, et al.; Panel Members. Tailoring therapies-improving the management of early breast cancer: St Gallen International Expert Consensus on the Primary Therapy of Early Breast Cancer 2015. Ann Oncol 2015;26:1533-1546

35. Konecny G, Pauletti G, Pegram M, Untch M, Dandekar S, Aguilar Z, et al. Quantitative association between HER-2/neu and steroid hormone receptors in hormone receptor-positive primary breast cancer. J Natl Cancer Inst 2003;95:142-153

36. Eiermann W, Rezai M, Kümmel S, Kühn T, Warm M, Friedrichs $K$, et al. The 21-gene recurrence score assay impacts adjuvant therapy recommendations for ER-positive, node-negative and node-positive early breast cancer resulting in a risk-adapted change in chemotherapy use. Ann Oncol 2013;24:618-624

37. Sparano JA, Gray RJ, Makower DF, Pritchard KI, Albain KS, Hayes DF, et al. Prospective validation of a 21-gene expression assay in breast cancer. N Engl J Med 2015;373:2005-2014

38. Stemmer S, Steiner M, Rizel S, Ben-Baruch N, Soussan-Gutman L, Rosengarten 0, et al. 1963 first prospective outcome data in 930 patients with more than 5 year median follow up in whom treatment decisions in clinical practice have been made incorporating the 21-gene recurrence score. European Journal of Cancer 2015;51:S321

39. Stemmer S, Steiner M, Rizel S, Soussan-Gutman L, Geffen DB, Nisenbaum B, et al. Abstract P5-08-02: real-life analysis evaluating 1594 No/Nmic breast cancer patients for whom treatment decisions incorporated the 21-gene recurrence score result: 5 -year KM estimate for breast cancer specific survival with recurrence score results $\leq 30$ is $>98 \%$. Cancer Research 2016;76(4 Suppl):Abstract nr P5-08-02

40. Gluz 0, Nitz UA, Christgen M, Kates RE, Shak S, Clemens M, et al. West German Study Group phase III planB trial: first prospective outcome data for the 21-gene recurrence score assay and concordance of prognostic markers by central and local pathology assessment. J Clin Oncol 2016;34:2341-2349

41. Petkov VI, Miller DP, Howlader N, Gliner N, Howe W, Schussler $\mathrm{N}$, et al. Breast-cancer-specific mortality in patients treated based on the 21-gene assay: a SEER population-based study. NPJ Breast Cancer 2016;2:16017

42. Drukker CA, Bueno-de-Mesquita JM, Retèl VP, van Harten WH, van Tinteren $\mathrm{H}$, Wesseling $\mathrm{J}$, et al. A prospective evaluation of a breast cancer prognosis signature in the observational RASTER study. Int J Cancer 2013;133:929-936

43. Filipits M, Rudas M, Jakesz R, Dubsky P, Fitzal F, Singer CF, et al.; EP Investigators. A new molecular predictor of distant recurrence in ER-positive, HER2-negative breast cancer adds independent information to conventional clinical risk factors. Clin Cancer Res 2011;17:6012-6020

44. Dubsky P, Filipits M, Jakesz R, Rudas M, Singer CF, Greil R, et al.; Austrian Breast and Colorectal Cancer Study Group (ABCSG). EndoPredict improves the prognostic classification derived from common clinical guidelines in ER-positive, HER2negative early breast cancer. Ann Oncol 2013;24:640-647

45. Filipits M, Nielsen T0, Rudas M, Greil R, Stöger H, Jakesz R, et al.; Austrian Breast and Colorectal Cancer Study Group. The PAM50 risk-of-recurrence score predicts risk for late distant recurrence after endocrine therapy in postmenopausal women with endocrine-responsive early breast cancer. Clin Cancer Res 2014;20:1298-1305

46. Sestak I, Cuzick J, Dowsett M, Lopez-Knowles E, Filipits M, Dubsky $P$, et al. Prediction of late distant recurrence after 5 years of endocrine treatment: a combined analysis of patients from the Austrian breast and colorectal cancer study group 8 and arimidex, tamoxifen alone or in combination randomized trials using the PAM50 risk of recurrence score. J Clin Oncol 2015;33:916-922

47. Sgroi DC, Sestak I, Cuzick J, Zhang Y, Schnabel CA, Schroeder $B$, et al. Prediction of late distant recurrence in patients with oestrogen-receptor-positive breast cancer: a prospective comparison of the breast-cancer index (BCI) assay, 21-gene recurrence score, and IHC 4 in the TransATAC study population. Lancet Oncol 2013;14:1067-1076

48. Zhang Y, Schnabel CA, Schroeder BE, Jerevall PL, Jankowitz $\mathrm{RC}$, Fornander T, et al. Breast cancer index identifies earlystage estrogen receptor-positive breast cancer patients at risk for early- and late-distant recurrence. Clin Cancer Res 2013; 19:4196-4205

49. Mittendorf EA, Chavez-MacGregor M, Vila J, Yi M, Lichtensztajn DY, Clarke CA, et al. Bioscore: a staging system for breast cancer patients that reflects the prognostic significance of underlying tumor biology. Ann Surg Oncol 2017;24:3502-3509 